\title{
Systemic follicular lymphoma with cutaneous involvement
}

\section{Selma El Kadiri', Sara Elloudi', Soukaina Chhiti', Hanane Bay Bay', Fatima Zahra Mernissi', Amal Douida², Layla Tahiri², Nawal Hammas², Leila Chbani², Hind El Fatemi²}

${ }^{1}$ Department of Dermatology, CHU Hassan II, Fez, Morocco, ${ }^{2}$ Anatomopathology Department, CHU Hassan II, Fez, Morocco

Corresponding author: Selma El Kadiri, MD, E-mail: elkadiri-s@hotmail.com

\begin{abstract}
A 65-year-old woman was referred to our department with a one-year history of pruriginous erythematous lesions on her scalp, the trunk, and limbs. Dermatological examination revealed erythematous to violaceus, indurated, well-demarcated, smooth surface, plaques, nodules, and tumors on her scalp, trunk, neck, limbs. She had multiple lenticular axillars and cervical lymphatic nodes without hepatosplenomegaly. A skin biopsy revealed a nodular and diffuse dermal infiltrate of centroblasts with the positivity of the large lymphoid cells for CD20, Bcl-2, CD10, and CD30. CD15 was expressed by a few tumoral. Excision of the axillar lymphatic node showed effacement of normal lymph node architecture. Diagnosis of high-grade B cell lymphoma unclassifiable between Cutaneous Diffuse Large B-Cell Lymphoma and Hodgkin disease was made. The patient was referred to the department of oncology and treated with RCHOP regimen.
\end{abstract}

Key words: Systemic follicular lymphoma; Cutaneous involvement; Chimiotherapy

\section{INTRODUCTION}

Systemic follicular lymphoma constitutes a heterogeneous group of clinical presentations and their cutaneous manifestation is rare with less than $4 \%$ of patients developing skin involvement. Herein we report a case of Systemic follicular lymphoma with cutaneous involvement.

\section{CASE REPORT}

A 65-year-old woman, presented with a one-year history of pruriginous erythematous lesions on her scalp, the trunk, and limbs. These lesions had slowly increased in size and were unresponsive to topical corticosteroids. Her medical history was significant for para-articular chondroma of the knee. She denied recent fevers, night sweats, or unintentional weight loss. The physical examination revealed erythematous to violaceus, indurated, well-demarcated, smooth surface, plaques, nodules, and tumors on her scalp, trunk, neck, limbs (Fig. la and lb). She had multiple lenticular axillars and cervical lymphatic nodes without hepatosplenomegaly. In front of this clinical presentation, we thought about many diagnoses such us aggressive b cell lymphoma, mycosis fungoid, and lymphomatoid papulosis.

A punch biopsy specimen revealed a nodular and diffuse dermal infiltrate of centroblasts with larger, oval nuclei sparing of the epidermis (Fig. 2) admixed with small lymphocytes and few eosinophils (Fig. 3a and 3b). Immunohistochemical studies showed the positivity of the large lymphoid cells for CD20, Bcl-2, CD10, and CD30 (Fig. 4a - 4c). CD15 was expressed by a few tumoral cells and CD3, CD4, and CD8 by reactional $\mathrm{T}$ cells. ALK stain was negative.

Diagnosis of high-grade cutaneous B cell lymphoma unclassifiable between Cutaneous Diffuse Large B-Cell Lymphoma and Hodgkin disease was made.

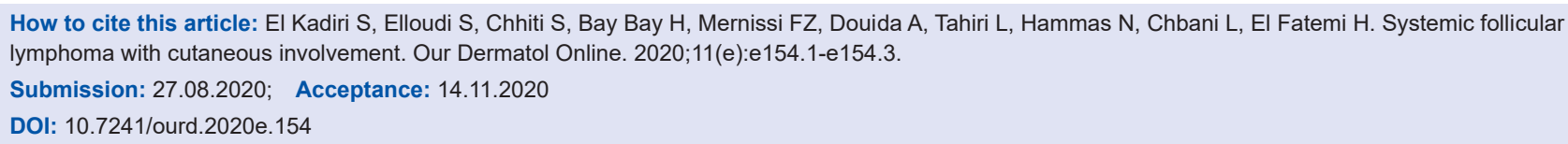




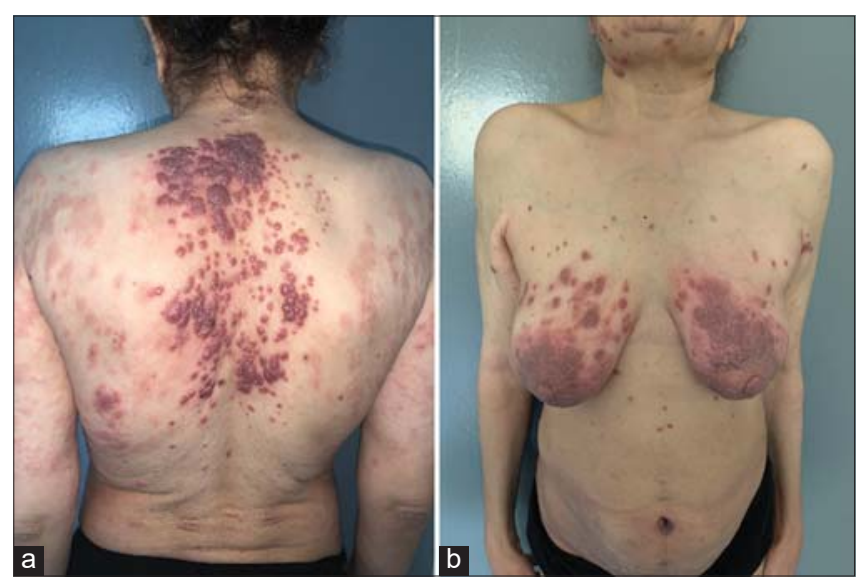

Figure 1: (a and b) Erythematous to violaceus, indurated, welldemarcated, smooth surface, plaques, nodules and tumor on her trunk.

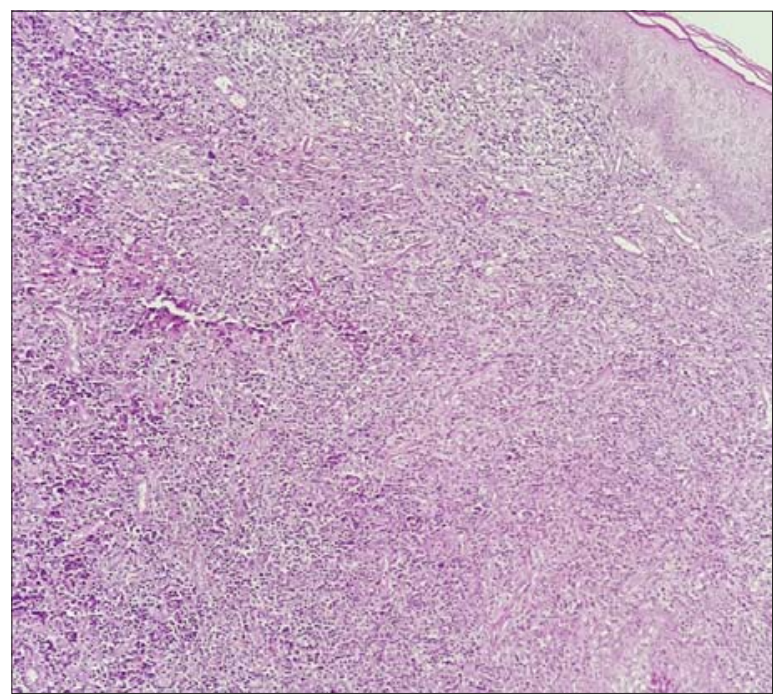

Figure 2: Diffuse and nodular dermal lymphoid infiltrate sparing of the epidermis (HES G x 200).

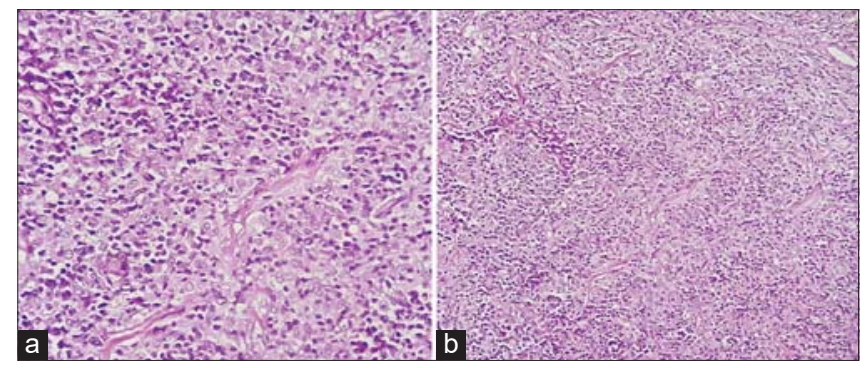

Figure 3: (a) Dense dermal and hypodermal lymphoid infiltrate consisting of enlarged centroblasts with larger, oval nuclei admixed with small lymphocyts and few eosinophils (HES G $\times 200$ ); (b) more close up (HES G x 400).

A subsequent blood cell count, chemistries, lactate dehydrogenase, and serum protein electrophoresis values were normal. Lymph node ultrasound revealed malignant lymphadenopathy at the right cervical measuring $1.5 \mathrm{~cm}$. Excision was performed showing effacement of normal lymph node architecture. The neoplastic cells comprise a mixture of large cells, few Reed-Sternberg-like cells, small lymphocytes, and eosinophils with an expression of CD20, CD30, CD10, and CD15 (Fig. 5 and 6).

The patient was referred back to the department of oncology, where she was treated with RCHOP (Rituximab, cyclophosphamide, doxorubicin, vincristine, and prednisone) regimen. The follow-up is in progress.

\section{DISCUSSION}

Primary cutaneous BCLs (PCBCLs) is a type of nonHodgkin lymphoma (NHL) are defined as malignant B-cell proliferation presenting with cutaneous involvement alone, without evidence of extracutaneous manifestations when complete staging has been performed [1].

However, when the disease presents with the lymph node and extranodal involvement, lymph node biopsy should be preferred [2]. In all cases, a surgical biopsy seems preferable because of the cellular and architectural heterogeneity possible within the same ganglion and as well as the possibility of detecting the areas of large cells that could make suspect a histological transformation [3].

It is important to rule out systemic BCL as a cause of skin lesions because, compared to PCBCL, it often displays a more aggressive clinical behavior, thereby requiring a different therapeutic approach. In fact, because of the rarity of PCBCL, skin lesions should be considered as secondarily spread from a systemic lymphoma until proven otherwise [4]. An appropriate laboratory workup to exclude systemic disease includes computed tomographic scans of the chest, abdomen, and pelvis, a complete blood cell count, blood chemistries, lactate dehydrogenase, and bone marrow aspirate with gene rearrangement studies [5].

While the cutaneous involvement of PCBCL is well documented, there are only a few publications of the systemic involvement of BCL [6,7]. In our case, they were patches, plaques, nodules, and tumors with extensive involvement of the scalp, trunk, and limbs. 


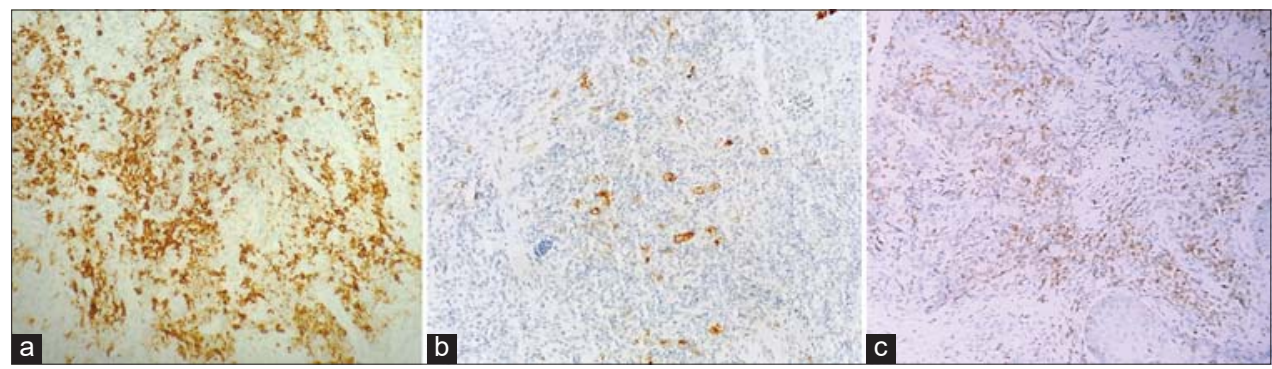

Figure 4: $(\mathrm{a}-\mathrm{c})$ Immunohistochemistry revealed positivity of the large lymphoid cell for CD20, Bcl-2, CD10.

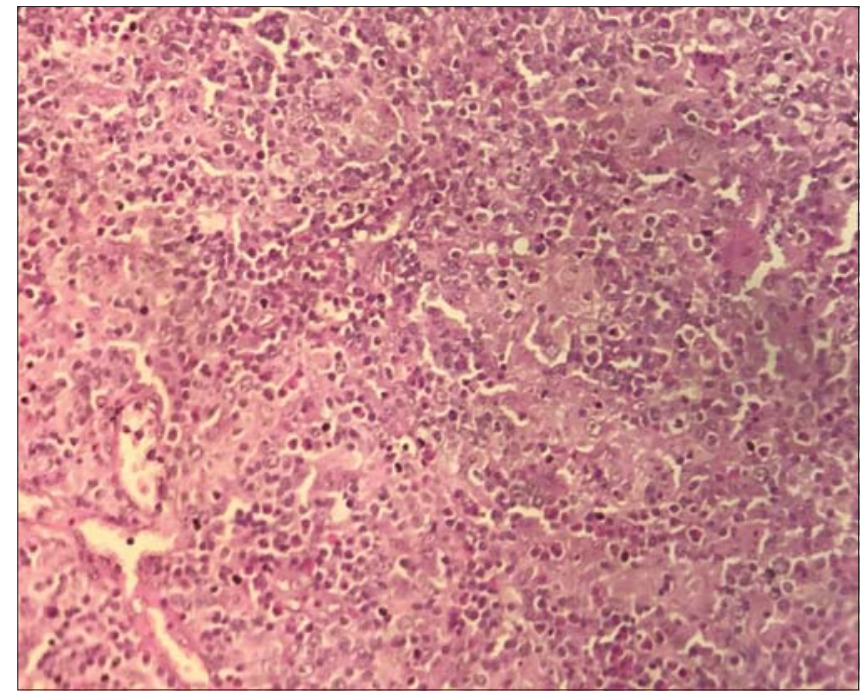

Figure 5: Follicular lymphoma with an effacement of normal lymph node architecture (HES G x 100).

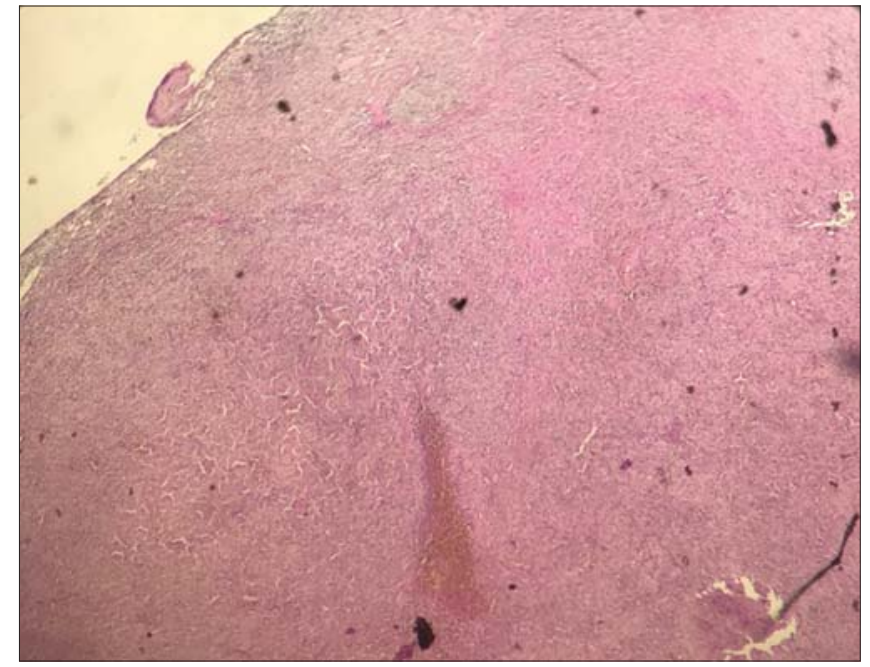

Figure 6: The neoplastic cells comprise a mixture of large cells, few Reed-Sternberg-like cells, small lymphocyts and eosinophils.

\section{CONCLUSION}

To the best of our knowledge, this is the first description of the cutaneous involvement of Systemic BCL unclassifiable between Cutaneous Diffuse Large
B-Cell Lymphoma and Hodgkin disease. through our observation, we want to highlight the importance of exclusion of a systemic BCL especially if cutaneous involvement includes extensive tumors, plaques, and nodules.

\section{Consent}

The examination of the patient was conducted according to the principles of the Declaration of Helsinki.

The authors certify that they have obtained all appropriate patient consent forms, in which the patients gave their consent for images and other clinical information to be included in the journal. The patients understand that their names and initials will not be published and due effort will be made to conceal their identity, but that anonymity cannot be guaranteed.

\section{REFERENCES}

1. Zackheim HS, Vonderheid EC, Ramsay DL, LeBoit PE, Rothfleisch J, et al. Relative frequency of various forms of primary cutaneous lymphomas. J Am Acad Dermatol. 2020;43:793-6.

2. Swerdlow SH, Campo E, Pileri SA, Harris NL, Stein H, Siebert R, et al. The 2016 revision of the World Health Organization classification of lymphoid neoplasms. Blood. 2016;127:2375-90.

3. Zinzani PL, Quaglino P, Pimpinelli N, Berti E, Baliva G, Rupoli S, et al; Italian Study Group for Cutaneous Lymphomas. Prognostic factors in primary cutaneous B-cell lymphoma: the Italian Study Group for Cutaneous Lymphomas. J Clin Oncol. 2006;24:1376-82.

4. Chaoui R, Elloudi S, El Kadiri S, Douhi Z, Baybay H, Mernissi FZ. Systemic anaplastic large celllymphomas ALK negativerevealed by a skin mass. Our Dermatol Online. 2020;11:e40.1-e40.3.

5. Oluwole OO, Zic JA, Douds JJ, Ann Thompson M, Greer JP. Cutaneous manifestations and management of hematologic neoplasms. Semin Oncol. 2016;43:370-83.

6. Rickaby RW, Calonje E. Cutaneous involvement from systemic lymphoma. Br J Dermatol. 2015;173:12-3.

7. Xie Y, Pittaluga S, Jaffe ES. The histological classification of diffuse large B-cell lymphomas. Semin Hematol. 2015;52:57-66.

Copyright by Ana Maria Abreu-Velez, et al. This is an open-access article distributed under the terms of the Creative Commons Attribution License, which permits unrestricted use, distribution, and reproduction in any medium, provided the original author and source are credited.

Source of Support: Nil, Conflict of Interest: None declared. 